\title{
BIOTECNOLOGIA: NOVO PARADIGMA DO AGRONEGÓCIO BRASILEIRO
}

\author{
Wellington Silva Gomes ${ }^{1}$ \\ Aluízio Borém ${ }^{2}$
}

RESUMO: O presente trabalho visa discutir como o emprego da biotecnologia moderna, no que concerne o desenvolvimento de variedades geneticamente modificadas, tornou-se estratégia importante para o fortalecimento do agronegócio brasileiro e mundial. Nesse sentido, aborda-se o histórico dos avanços do agronegócio mundial e brasileiro, com a implantação e comercialização dos produtos vegetais derivados da biotecnologia. O Brasil, um país rico em biodiversidade, considerado também celeiro mundial de alimentos tem se destacado no cenário internacional pelas pesquisas e desenvolvimento de produtos no campo da engenharia genética e genômica. Além disso, esse trabalho demostra como o emprego da biotecnologia tem sido importante para o desenvolvimento de sistemas agrícolas mais produtivos e sustentáveis, beneficiando pequenos e grandes produtores, aumentando assim a competitividade brasileira no mercado internacional. Por fim, as perspectivas do mercado biotecnológico para o agronegócio brasileiro são discutidas e analisadas buscando soluções para se desenvolver um país com alta produção agrícola agregando as recentes ferramentas biotecnológicas.

Palavras-chave: Biotecnologia, OGMs, agronegócio, transgênicos, mercado internacional, competitividade.

ABTRACT: The aim of this paper is discuss how to the application of the modern biotechnology, especially of genetically modified varieties became an important strategy for the strength of the Brazilian agribusiness and worldwide. In this regard, it is addressed the global agribusiness and Brazilian history progress, with the deployment of biotechnology-derived plant varieties. Brazil, a biodiversity rich country is also regarded as a food source for the world, has emerged as a biotechnology power in the international scenario. Furthermore, this essay shows how the use of biotechnology has been important for the development more productive and sustainable agriculture, benefiting from small to large farmers, and increasing the Brazilian competitiveness in the international market. Finally, the market outlook for the biotech agribusiness are discussed and analyzed.

Key-words: Biotechnology, OGMs, agribusiness, transgenics, global market, competitiveness.

1 Biólogo, M.S, D.S. e Bolsista de Pós-Doutorado da Universidade Federal do Espírito Santo. E-mail: wsgomes7@ gmail.com

2 Engenheiro Agrônomo, M.S., Ph.D. e Professor da Universidade Federal de Viçosa. E-mail: borem@ufv.br 


\section{Introdução}

Embora o termo biotecnologia, em seu sentido amplo seja recente, relatos sobre seus usos datam-se de seis mil anos, no qual microorganismos eram utilizados em processos fermentativos para produção da cerveja e do pão, dentre outros produtos. Hoje, com os avanços da biotecnologia moderna, muitas oportunidades de crescimento para diversos setores da economia foram criadas, entre as quais se destaca a agricultura, que tem como maior desafio aumentar a produção de alimentos com o uso sustentável da nossa biodiversidade.

O uso comercial de plantas geneticamente modificadas é um dos grandes marcos da agricultura nos últimos anos. Atualmente, a produção de transgênicos está distribuída em praticamente todas as regiões agricultáveis do planeta e a biotecnologia tem atingido níveis nunca alcançados por outras tecnologias avançadas, em toda história da agricultura. Desde o primeiro plantio comercial em 1994, a área global de cultivos GM atingiu cerca de 170 milhões de hectares em 2012. Atualmente o Brasil se desponta como o segundo maior produtor de variedades transgênicas no mundo.

Nesse sentido, o emprego da biotecnologia, principalmente no que se refere a produtos e processos derivados da engenharia genética é de importância estratégica para o agronegócio brasileiro e mundial. O desenvolvimento de variedades transgênicas resistentes a pragas, patógenos e tolerantes a herbicidas tem figurado como uma das tecnologias responsáveis pela redução das perdas nas lavouras, provocando a diminuição dos custos da produção, bem como, na conservação do ambiente, fazendo com que produtores e consumidores possam obter alimentos com menor custo e atendendo ao desafio atual da preservação do ambiente e inocuidade alimentar. 


\section{Histórico do Agronegócio Mundial}

Por muitos anos, a agricultura era baseada em propriedades agrícolas autossustentáveis onde todos os recursos necessários e fatores de produção eram desenvolvidos internamente. Dessa forma, além de produzir os alimentos, elas produziam também equipamentos, implementos agrícolas, insumos básicos, processamento e comercialização do produto, tornandose assim, autônomos em relação aos demais ramos.

Com a modernização dos centros urbanos, o aumento populacional e o desenvolvimento da indústria mundial, a especialização setorial da agricultura tornou-se fator importante para aumentar a eficiência e distribuição dos produtos agropecuários. Nesse sentido, a agricultura se transformou em um fator de valor com ramos bem especializados que buscam fazer a ligação entre o que é produzido nas propriedades rurais e os subprodutos para a indústria e comércio.

Essa concepção de agricultura como sendo o setor provedor de alimentos e matérias-primas para consumo interno ou para exportação foi responsável pela intensificação da economia, que hoje representa grande parcela do Produto Interno Bruto - PIB (cerca de 35\% do PIB dos países em desenvolvimento e $18 \%$ dos países ricos), referentes às importações e exportações de produtos agrícolas (insumo, produção, processamento e distribuição) (FMI, 2013).

Assim, um novo conceito foi criado para referenciar toda essa cadeia econômica sobre os bens derivados da agricultura, o agronegócio. Também denominado agrobusiness, esse termo consiste em toda relação comercial e industrial que envolve todos os segmentos da cadeia produtiva vinculada à agropecuária sob o ponto de vista econômico.

O estudo do agronegócio é tecnicamente dividido em três partes: a primeira parte trata dos negócios agropecuários propriamente ditos, que representam os produtores rurais, detentores de pequenas, médias ou grandes propriedades, constituídos na forma de pessoas físicas (fazendeiros 
ou camponeses) ou de pessoas jurídicas (empresas). Na segunda parte, os negócios à montante da agropecuária, representados pela indústria e comércio que fornecem insumos rurais, fabricam máquinas rurais, fornecem defensivos agrícolas, sementes, equipamentos, etc. Na terceira parte estão os negócios à jusante dos negócios agropecuários, onde estão a compra, transporte, processamento, distribuição e comercialização dos produtos agropecuários até o consumidor final.

O agronegócio no mundo tornou-se um dos setores mais importantes da economia de muitos países. Para se ter ideia da dimensão de sua importância, se somássemos todos os setores envolvidos neste contexto, desde a produção nas fazendas até a distribuição, teríamos um lucro superior ao PIB dos Estados Unidos (US\$15 trilhões). No contexto brasileiro, a soma dessas cadeias produtivas é de aproximadamente US\$900 bilhões (CEPEA, 2012), o que representa, comparativamente, ao $20^{\circ}$ maior PIB mundial, constituídos por países como a Suíça, Suécia e Bélgica. Em comparação com a Argentina, um país com grande PIB agropecuário, o agronegócio brasileiro é cerca de 50\% maior do que todo PIB da Argentina.

A previsão do PIB mundial para 2013 é de crescer cerca de 4\%. Em 2012, a balança comercial universal foi cerca de US\$71,3 trilhões. Especulações de mercados internacionais afirmam que em 2013, pela primeira vez, o PIB dos países em desenvolvimento vai ultrapassar o PIB dos países desenvolvidos, segundo dados do Fundo Monetário Internacional, devido ao crescimento da contribuição do agronegócio no PIB desses países (FMI, 2013).

Em 2012, as economias dos países desenvolvidos representavam 50,2\% do total da economia mundial com uma população de aproximadamente 1 bilhão de habitantes e uma renda per capita anual de 40 mil dólares. Em contrapartida, as economias de países em desenvolvimento representavam 49,8\% do PIB mundial, com uma população superior a 6 bilhões de habitantes e uma renda per capita de 7 mil dólares. Isto acontece porque os países em desenvolvimento, embora possuam 
renda per capita inferior aos primeiros, apresentam maiores taxas de crescimento anual. Em 2012, o PIB dos países ricos cresceu somente $1,3 \%$ e as previsões apontam para $1,5 \%$ em 2013. No mesmo período o crescimento anual da economia dos países em desenvolvimento foi de $5,6 \%$, principalmente pelo aquecimento das economias chinesas e indianas (FMI, 2013).

Esse crescimento observado nos países em desenvolvimento pode ser reflexo do aumento das áreas de lavouras transgênicas. Os países desenvolvidos representaram $48 \%$ de toda a área plantada de organismos geneticamente modificados, em contrapartida, os países em desenvolvimento representaram 52\% do montante mundial. Em 2012, a taxa de crescimento para culturas biotecnológicas foi pelo menos três vezes mais rápido, e cinco vezes maior nos países em desenvolvimento, ou seja, incremento de $11 \%$ ou 8,7 milhões de hectares, contra $3 \%$ ou 1,6 milhões de hectares nos países industrializados (JAMES, 2012).

Com a demanda dos países emergentes e o ritmo atual do aquecimento global, países como a Índia e China aumentarão a demanda por alimentos, e nesse sentido, órgãos internacionais calculam que será necessário aumentar em 20\% a oferta de alimentos no planeta, até 2020 (FEU-US, 2011). Países como o Brasil e Argentina, com o pleno uso das tecnologias de engenharia genética vêm crescendo vertiginosamente e auxiliarão nesse aumento substancial de alimentos, e consequentemente farão com que o PIB do agronegócio seja o maior responsável pelos lucros da balança comercial favorável nesses países.

\section{Comercialização de Organismos Geneticamente Modificados no Mundo}

A aplicação da moderna biotecnologia vem se mostrando essencial para assegurar a competitividade dos países exportadores de alimentos nos mercados do agronegócio. $\mathrm{O}$ rápido desenvolvimento de culturas geneticamente modificadas durante os últimos anos tem permitido aos 
agricultores, reduzir seus custos de produção e elevar os índices de produtividade devido à diminuição de perda no campo.

As primeiras plantas transgênicas foram obtidas no início da década de 1980 e sua comercialização iniciou-se a partir de 1994, nos Estados Unidos, com a aprovação para comercializar um alimento geneticamente modificado, o tomate "Flavr Savr", que apresentava o amadurecimento retardado, resultando na diminuição das perdas no transporte e comércio. Em 17 anos, a área mundial de cultivos de transgênicos passou de 1,7 milhão de hectares em 1996 para cerca de 170 milhões de hectares em 2012,com avanços gradativos a cada ano (JAMES, 2012). No mundo, 28 países, dos quais, 8 industrializados e 20 em desenvolvimento, plantam alguma variedade transgênica (Figura 1).

\section{ÁREA GLOBAL DE VARIEDADES TRANSGÊNICAS em milhöes de hectares (1996-2012)}

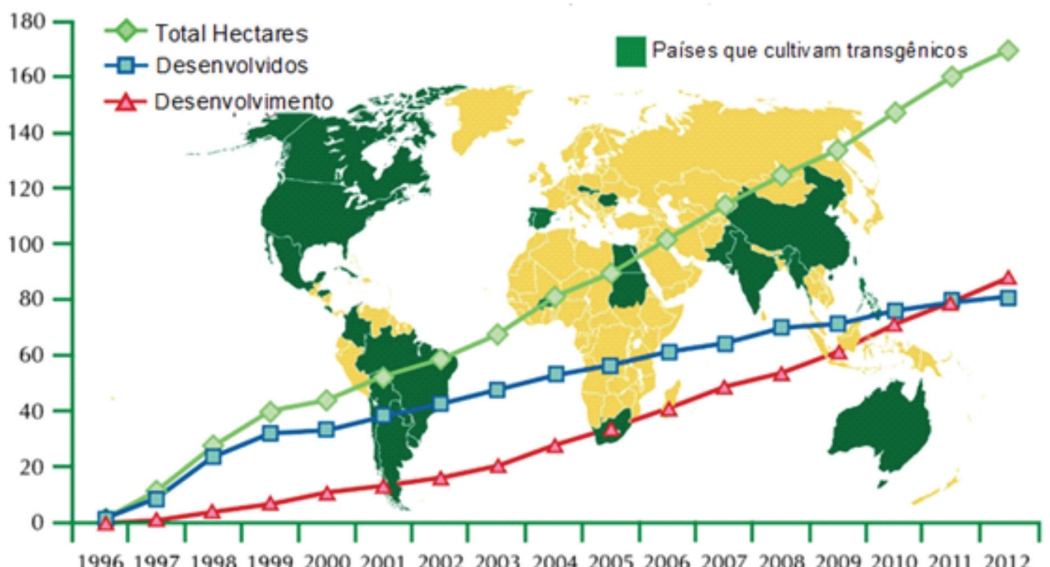

Em 2012, 28 paises plantaram 170,3 milhöes de hectares de plantas geneticamente modificadas, um aumento de $6 \%$ ou 10,3 milhōes de hectares em relação a 2011.

Figura 1: Área Global dos países produtores de variedades geneticamente modificadas em 2012.

Fonte: JAMES, 2012 
Os Estados Unidos é, atualmente, o país com a maior área de transgênicos no mundo. Em 2011, foram plantados mais de 69 milhões de variedades transgênicas no país. O Brasil e a Argentina, segundo e terceiro países com maior área de transgênicos, plantaram respectivamente 36,6 e 23,9 milhões de hectares. Esses três países contribuíram com $78 \%$ da área plantada com cultivares GM no mundo (JAMES, 2012). Mais da metade da população mundial, cerca de $60 \%$ ou 4 bilhões de pessoas, vivem em um dos 28 países que cultivam culturas biotecnológicas (Tabela 1).

Tabela 1: Área Global de Culturas Transgênicas em 2012: por País (Milhões de Hectares).

\begin{tabular}{|c|c|c|c|}
\hline Classificação & País & $\begin{array}{c}\text { Área } \\
\text { (milhões de hectares) }\end{array}$ & Espécies \\
\hline 1 & USA* $^{*}$ & 69,5 & Milho, soja, algodão, canola, beterraba, alfafa, mamão e abóbora \\
\hline 2 & Brasil* & 36,6 & Milho, soja e algodão \\
\hline 3 & Argentina* & 23,9 & Milho, soja e algodão \\
\hline 4 & Canada* & 11,6 & Milho, soja, canola e beterraba \\
\hline 5 & Índia* & 10,9 & Algodão \\
\hline 6 & China* & 4 & Algodão, mamão, álamo, tomate e pimentão \\
\hline 7 & Paraguai* & 3,4 & Soja \\
\hline 8 & África do Sul* & 2,9 & Milho, soja e algodão \\
\hline 9 & Paquistão* & 2,8 & Algodão \\
\hline 10 & Uruguai* & 1,4 & Milho e soja \\
\hline 11 & Bolívia* & 1,0 & Soja \\
\hline 12 & Chile & 1 & Milho, soja e canola \\
\hline 13 & Filipinas* & 0,8 & Milho \\
\hline 14 & Austrália* & 0,7 & Algodão e canola \\
\hline 15 & Burquina Faso* & 0,2 & Algodão \\
\hline 16 & Mianmar * & 0,3 & Algodão \\
\hline 17 & México* & 0,2 & Soja e Algodão \\
\hline 18 & Espanha* & 0,1 & Milho \\
\hline 19 & Colômbia & $<0,05$ & Algodão \\
\hline 20 & Honduras & $<0,05$ & Milho \\
\hline 21 & Sudão & $<0,05$ & Algodão \\
\hline 22 & Portugal & $<0,05$ & Milho \\
\hline 23 & República Tcheca & $<0,05$ & Milho \\
\hline 24 & Cuba & $<0,05$ & Milho \\
\hline 25 & Egito & $<0,05$ & Milho \\
\hline 26 & Costa Rica & $<0,05$ & Soja e Algodão \\
\hline 27 & Romênia & $<0,05$ & Milho \\
\hline \multirow[t]{2}{*}{28} & Eslováquia & $<0,05$ & Milho \\
\hline & Total & 160 & \\
\hline
\end{tabular}

Fonte: JAMES, 2012.

Mundialmente, inúmeras culturas geneticamente modificadas estão sendo comercializadas, tais como: soja, milho, algodão, arroz, batata, 
canola, beterraba, alfafa, mamão, abóbora, tomate, pimentão e a espécie florestal álamo. Vale ressaltar que as principais commodities soja, milho, algodão e canola representam cerca de $95 \%$ de toda a área plantada de transgênicos no mundo. Entretanto, outras já foram liberadas ou estão em processo de pesquisa, como: feijão, café, cana-de-açúcar, trigo, canola, banana, maçã, alface, eucalipto, entre outras. Novos produtos vêm sendo desenvolvidos para a liberação, e o foco principal são para espécies de grande importância no país, buscando assim, o fortalecimento de economias regionais.

A soja é a variedade transgênica mais cultivada no mundo, ocupando cerca de 75,4 milhões de hectares, o que representa 47\% da área global de cultivos transgênicos. Em segundo lugar, encontra-se o milho (51 milhões de hectares, 32\%), seguido pelo algodão (24,2 milhões de hectares, 15\%) e a canola $(8,2$ milhões de hectares, $5 \%$ ). As características agronômicas mais introduzidas em variedades transgênicas são a tolerância a herbicidas, resistência a insetos ou as duas características combinadas, que representam 59\%, 15\% e 26\%, respectivamente, da área plantada mundialmente (JAMES, 2011).

No final de dezembro de 2012, autoridades americanas da FDA (Food and Drug Administration) aprovaram o consumo de um tipo de salmão geneticamente modificado. Este produto ainda não está sendo comercializado, mas trata-se do primeiro animal geneticamente modificado a ser utilizado para consumo humano, aumentando assim, a gama de gêneros alimentícios que a biotecnologia pode oferecer para aumentar a produção de alimentos (FDA, 2013).

\section{O Agronegócio Brasileiro e a Adoção da Biotecnologia}

Nas últimas décadas, a economia brasileira sofreu transformações no que se refere à atividade produtiva agropecuária e de seus mercados nacionais e internacionais. Tal tendência demanda crescente articulação dentro e entre setores na busca por ganhos de competitividade sistêmica. 
O agronegócio brasileiro vem apresentando resultados bastante significativos na contribuição ao saldo da balança comercial que dependem de forma crescente, de que um amplo conjunto de instituições funcione de maneira adequada e articulada.

A agricultura brasileira obteve padrões de excelência e competitividade que foram se impondo a partir do processo de internacionalização do agronegócio. Após o declínio econômico na década de 1960, houve maior abertura da economia brasileira, incorrendo na necessidade da implementação de políticas públicas ativas para a viabilização do salto tecnológico centrado no melhoramento genético e na intensificação do uso de insumos modernos, bem como das políticas de crédito rural e de assistência técnica pública, de pesquisa e desenvolvimento apropriados à agricultura tropical e políticas de implantação de indústrias de insumos básicos (fertilizantes, corretivos, defensivos agrícolas, etc.) (BAER, 2002).

Nesse contexto, o agronegócio brasileiro tornou-se um segmento com grande representatividade econômica. Conforme dados divulgados em 2012 pelo Centro de Estudos Avançados em Economia Aplicada (CEPEA), o agronegócio é responsável por aproximadamente $21 \%$ do PIB nacional e representam 35,1\% das exportações brasileiras. O país é um dos líderes mundiais nesse setor, exportando para mais de 180 nações (GPD AGRIBUSSINES, 2012).

As exportações de produtos agropecuários cresceram aproximadamente 190\% entre os anos de 2000 e 2012. O saldo comercial (receitas de exportação menos gastos com importação) mais que quintuplicou, com crescimento de 460,83\% (Figura 2). No acumulado, foram gerados líquidos US\$481 bilhões, sendo US\$79 bilhões só em 2012 (BARROS; ADAMI, 2013). 


\section{Evolução da Balança Comercial (BC) do Agronegócio}

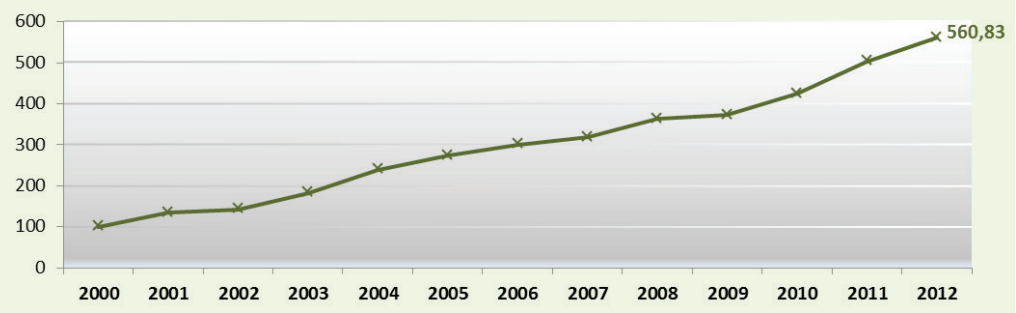

Figura 2: Evolução do saldo comercial do agronegócio brasileiro entre os anos de 2000 e 2012.

Fonte: BARROS \& ADAMI, 2012-Cepea/Esalq-USP

Segundo o Ministério do Desenvolvimento, Indústria e Comércio Exterior, em 2012, as exportações brasileiras do agronegócio somaram US $\$ 95,8$ bilhões, com aumento de 1\% em relação a 2011. Entretanto, esse valor é 24\% superior do verificado em 2010 (de US\$76,4 bilhões). Isto resultou em um superávit recorde de US\$79,41 bilhões, mesmo com todos os problemas relacionados à infraestrutura encontrados.

O maior crescimento percentual de arrecadação com a exportação foi obtido com a venda de milho, soja, fumo, cereais, café, fibras, produtos têxteis e carne. O milho foi o maior responsável por esse aumento, devido, principalmente, a baixa produção nos Estados Unidos, em decorrência da seca ocorrida em 2012. O valor arrecadado no exterior, somente com este cereal ultrapassou US\$ 5,29 bilhões. A pecuária teve também grande importância: as vendas de carne bovina registraram alta de 7,4\% no faturamento das exportações, somando US\$5,74 bilhões em 2012 (GPD AGRIBUSSINES, 2012) (Figura 3). 


\section{Setor Agropecuário}

Produção no Brasil entre 2010 e 2011

Soja

salra 2010/2011

74,8 milhões

de toneladas

Mato Grosso

maisr estado prosutor

20,4 milhões

de toneladas

Fonte: CONAB
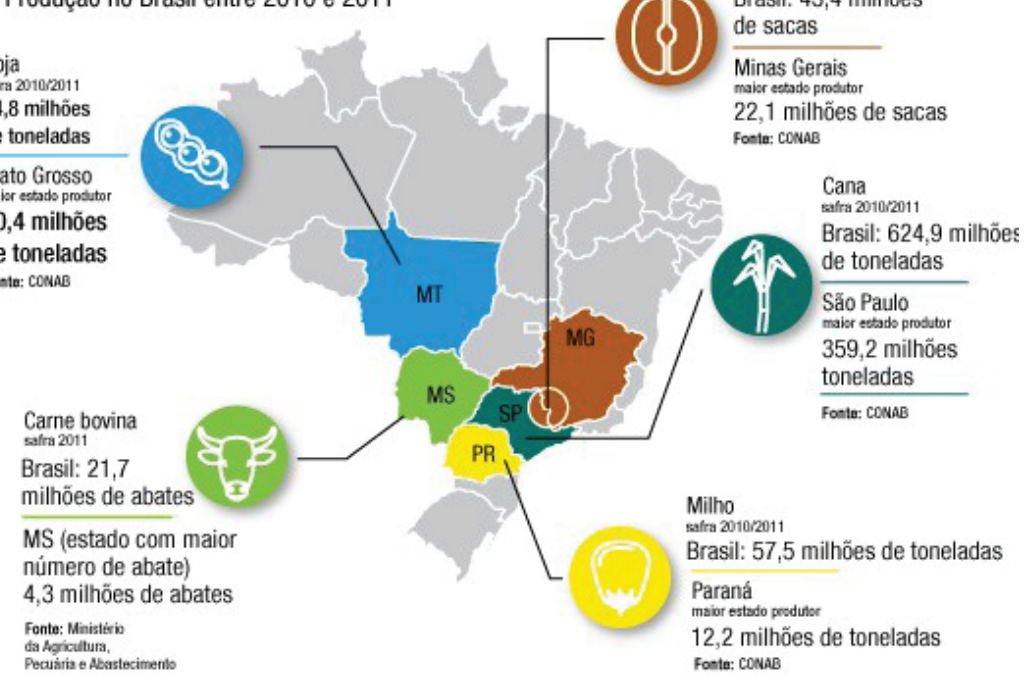

Café

salra 2011

Brasil: 43,4 milhöes

de sacas

Minas Gerais

misir ectado prositor

22,1 milhões de sacas

Fonte: CONAB

Figura 3: Produção agropecuária brasileira entre os anos de 2010 e 2011. Fonte: Ministério da Agricultura, Pecuária e Abastecimento, 2011.

O principal destino dos produtos do agronegócio brasileiro continua sendo os países europeus, com participação de $21,6 \%$ da receita gerada, percentual ligeiramente inferior ao do ano anterior (2011) que foi de $22,4 \%$. A China aumentou sua participação, absorvendo $18,7 \%$ do total exportado pelo agronegócio brasileiro, configurando-se ainda como maior destino dos produtos do setor, quando considerados países isolados. O terceiro principal destino continua sendo os Estados Unidos, com participação de 7,4\% do total. Além destes, os outros importantes destinos em 2012 foram: Japão, Rússia, Arábia Saudita, Coréia do Sul, Venezuela, Hong Kong e Irã (Figura 4). 


\section{Principais destinos do agronegócio em 2012}

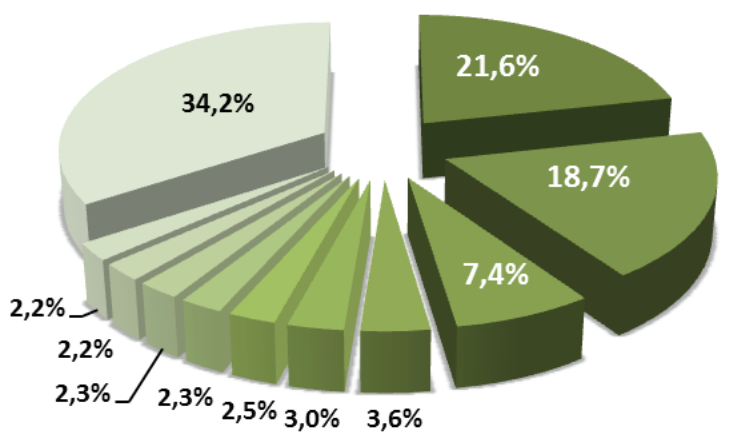

- Zona do Euro

China

Estados Unidos

- Japão

- Rússia

Arábia Saudita

Coréia do Sul

Venezuela

Hong Kong

Irã

Demais países

Figura 4 - Principais destinos das exportações do agronegócio brasileiro em 2012 conforme receita gerada.

Fonte: BARROS \& ADAMI, 2012-Cepea/Esalq-USP

Nesse contexto, é importante ressaltar o que o crescimento das exportações de soja, milho e algodão no Brasil foi impulsionado principalmente pelo desenvolvimento de plantas geneticamente modificadas que foram liberadas de forma mais consistentes a partir de 2005, com a criação da nova Lei de Biossegurança. Dois anos após a definitiva liberação do cultivo de transgênicos, o Brasil já cultivava 3,5 milhões hectares na área plantada apenas com soja geneticamente modificada. Tratava-se, assim, segundo dados do Serviço Internacional para a Aquisição de Aplicações em Agrobiotecnologia, do maior aumento nominal registrado em culturas de transgênicos no mundo.

Assim, o Brasil está emergindo como um líder global em culturas biotecnológicas. Pelo terceiro ano consecutivo, o país foi o motor do crescimento global em 2011, aumentando sua área plantada mais do que qualquer outro país no mundo, com um aumento recorde de 4,9 milhões hectares, em relação a 2010, o que equivale ao incremento de $20 \%$ e representando $19 \%$ da área global de cultivo de transgênicos, 
tornando-se o segundo maior produtor de organismos geneticamente modificados no mundo.

Um sistema de aprovação adotado pelo governo (CTNBio) permitiu que o Brasil aprovasse com critérios rígidos oito eventos de transgenia em 2010, e em 15 de outubro de 2011, um adicional de 6 eventos foram aprovados em 2011. O Brasil aprovou, também, a soja com resistência a insetos e tolerância a herbicidas para comercialização em 2012. Cerca de $89 \%$ de toda a soja plantada no Brasil é transgênica. Para o milho, a porcentagem representa aproximadamente $76 \%$ e, para o algodão cerca de metade das lavouras são formadas por cultivares geneticamente modificados (CÉLERES, 2012).

Desde a criação da CTNBio, em 1995, cerca de 60 organismos geneticamente modificados, dos quais 40 são plantas, foram liberados para a comercialização. Os critérios de liberação desses organismos no país estão entre os mais rigorosos do mundo. As alterações genéticas realizadas nas plantas disponíveis no mercado atualmente, quase sempre têm como objetivo as tornarem mais resistentes, seja a agrotóxicos, a pragas ou às intempéries climáticas.

\section{Benefícios da Biotecnologia para Pequenos e Grandes Produtores}

A adoção e o aumento no plantio de variedades transgênicas, verificados ano após ano é justificado pelo menor custo de produção e, muitas vezes rendem mais que as convencionais, devido à diminuição da perda por ataques de lagartas ou competição por plantas daninhas.

Um estudo desenvolvido pela Céleres Consultoria a pedido da Associação Brasileira de Sementes e Mudas (Abrasem), mostra que os benefícios econômicos do uso da biotecnologia na agricultura brasileira alcançaram US $\$ 18,8$ bilhões em 16 anos e $81 \%$ desse valor ficaram com os produtores rurais, restando $19 \%$ para a indústria. Como exemplos de valores reais 
aproximados, o retorno no milho foi de $\mathrm{R} \$ 3$ e na soja de $\mathrm{R} \$ 2,1$ para cada R\$ 1 investido pelo produtor. Essa redução de custos com menor perda na lavoura representa cerca de $30 \%$ e $51 \%$ dos US $\$ 18,8$ bilhões, respectivamente (CÉLERES, 2013).

Entre as variedades transgênicas plantadas no Brasil, mesmo sendo adotado tardiamente (2007), o milho lidera pelo segundo ano como o produto que gera maior lucro para o produtor, representando $58 \%$ do lucro total, ante aos $49 \%$ da safra 2010/11 e 32\% da safra 2009/10, demonstrando a representatividade deste cereal na biotecnologia agrícola brasileira. Em contrapartida, a soja responde por $39 \%$ do total, apresentando uma redução de importância, pois atingia $47 \%$ do total em 2010/11 e 65\% do total em 2009/10. O algodão, cuja adoção da biotecnologia começou em 2004/05, responde por $3 \%$ do benefício total, pois a área plantada é bem menor quando comparada a da soja e a do milho.

Pelas estimativas da Céleres Consultoria, o milho transgênico cobrirá 12,2 milhões de hectares no ciclo 2012/13, o equivalente a 76,1\% da área total do grão prevista pela consultoria para o período. Já em relação à projeção de área da Companhia Nacional de Abastecimento (Conab), que é de 14,7 milhões de hectares, o cereal geneticamente modificado representaria $82,3 \%$ das lavouras. A maior parte da produção é proveniente de grandes produtores, entretanto, benefícios serão ainda maiores para os pequenos produtores, que nem sempre conseguem aplicar os inseticidas a tempo de protegerem suas lavouras (CÉLERES, 2013).

Assim, o grande desafio do mercado brasileiro, no que se refere à adoção da biotecnologia para aumentar a área de plantio e consequentemente, o agronegócio brasileiro, é romper o viés ideológico que ainda afasta alguns agricultores do uso da biotecnologia. Esses agricultores representam entre $17,7 \%$ e $23,9 \%$ de toda a área utilizada para a agricultura no país.

No caso da soja transgênica, a produção é distribuída por boa parte do Brasil. Na região sul, nos estados do Rio Grande do Sul, Santa Catarina e Paraná, a maior parte da produção está concentrada nas mãos de pequenos 
e médios produtores. Já na região centro-oeste, nos estados de Goiás, Mato Grosso do Sul e Mato Grosso e no oeste da Bahia, prevalecem os grandes produtores.

Programas sociais administrados pelos governos estaduais e pelo Ministério do Desenvolvimento Agrário (MDA) distribuem sementes para pequenos produtores gratuitamente ou a preços reduzidos para que possam se autossustentar e obter lucro com a venda do produto. Nesse sentido, a agroindústria estuda estratégias para atingir o pequeno agricultor que recebe esse auxilio do governo, em especial no Rio Grande do Sul, Minas Gerais e em estados do Nordeste, haja vista que, as sementes geneticamente modificadas são $45 \%$ mais caras que as convencionais e são mais dependentes do uso de tecnologia, bem como de agroquímicos, aumentando assim, o círculo de possíveis clientes. Só no Rio Grande do Sul, a distribuição de sementes de milho para a agricultura familiar chega a 400 mil sacas por safra.

Uma das justificativas para a adoção dos transgênicos, segundo a Céleres Consultoria, é que a produção média nacional obtida por pequenos produtores possui rendimento baixo, na faixa de 2 mil quilos por hectare, enquanto produtores de grande porte que usam biotecnologia alcançam até 11 mil quilos por hectare. Deduzindo-se os impactos sobre a baixa tecnologia e a falta de mão de obra especializada presente em pequenas propriedades, um de seus relatórios indica que o benefício econômico acumulado da safra 2008/09 até 2011/12 somariam US\$100,4 mil somente em uma propriedade pequena de 50 hectares (CÉLERES, 2013).

Sobre esse valor, cerca de $90 \%$ referem-se ao ganho de produtividade e o restante divide-se entre a redução de custos com insumos e defensivos e a remuneração da indústria sementeira. E, mantidas as premissas atuais de aumento de eficiência, o benefício econômico pode alcançar US\$324,1 mil no acumulado de 2011/12 a 2021/22 na mesma plantação de 50 hectares.

Apenas no Rio Grande do Sul, a distribuição de sementes de milho para a agricultura familiar chega a 400 mil sacas por safra, o suficiente 
para plantar 400 mil hectares, ou 40\% da área total de milho no estado. Entretanto, apesar das agroindústrias terem disposição e interesse em fornecer sementes transgênicas para os programas governamentais, há resistência dos executores das políticas públicas, bem como de pequenos produtores desinformados.

No mundo, existem vários exemplos dos benefícios das variedades geneticamente modificadas para os pequenos produtores. $\mathrm{Na}$ Índia, antes um país importador, hoje a segunda nação que mais produz e vende algodão no mundo, a produtividade indiana aumentou 24\% entre 2002 e 2008, devido à redução de perdas causadas por pragas, demonstram que o número de pequenos produtores cresceu em até $50 \%$ nesse mesmo período, devido ao incentivo governamental e esclarecimento sobre o potencial da cultura geneticamente modificada. Além disso, o aumento da produtividade de algodão contribui ativamente para o desenvolvimento econômico e social do país, um dos mais populosos do mundo (KATHAGE; QAIM, 2012).

$\mathrm{Na}$ África do Sul, estudos indicam que o milho transgênico aumentou em $34 \%$ a produtividade de pequeno produtor. Segundo a Food and Agriculture Organization (FAO), no mundo, existem aproximadamente 500 milhões de pequenas propriedades rurais e cerca $85 \%$ destas fazendas são de pequena escala, operando com menos de dois hectares (NAGAYETS, 2005). Destes produtores, aproximadamente 9,3 milhões já utilizam sementes provenientes da biotecnologia agrícola e atestam que a tecnologia foi responsável por melhorar a forma de sobreviver no campo e aumentar a qualidade de vida, com maiores lucros (CIB, 2008).

Em 2012, 17,3 milhões de agricultores, 600 mil a mais que 2011, plantaram culturas biotecnológica. Vale ressaltar que, mais de $90 \%$, ou seja, 15 milhões eram compostos por pequenos agricultores com recursos e áreas escassos em países em desenvolvimento. Neste mesmo ano, um recorde de 7,2 milhões de pequenos agricultores na China e outros 7,2 milhão na Índia plantaram quase 15 milhões de hectares de algodão Bt, por causa dos benefícios significativos que oferece (JAMES, 2012). 
Portanto, há uma necessidade de se informar e incentivar pequenos produtores a adotarem o plantio de transgênicos e assim, aumentar a competitividade da agricultura de pequenos produtores, contribuindo para a redução da pobreza através da ciência e da tecnologia.

\section{Perspectivas do Mercado Biotecnológico para o Agronegócio Brasileiro}

É antiga a expectativa de que o Brasil, um dia, se tornaria o celeiro do mundo. Ela serviu de slogan para governos e tornou-se profecia de muitos, em especial, de Norman Borlaug, engenheiro agrônomo americano considerado o pai da "Revolução Verde", modelo que deu à agricultura a escala industrial desejada com o uso de fertilizantes e defensivos químicos a partir da década de 1960. Em um relatório da FAO, sobre Perspectivas Agrícolas 2010-2019, feito em conjunto com a OCDE (Organização para a Cooperação e Desenvolvimento Econômico) identificou que os produtores de soja brasileiros tendem a se tornar os maiores exportadores do grão em 2018, superando os Estados Unidos. Entretanto, com a ampla adoção das variedades transgênicas de soja o Brasil deve se tornar em 2013, cinco anos antes da estimativa inicial, o maior produtor mundial desta leguminosa.

A previsão de crescimento do setor agrícola brasileiro até o ano de 2019, segundo a FAO (2010) é de mais 40\%, em comparação aos anos 2007-2009. Nesse mesmo período grandes produtores como, China, Rússia e Índia não passarão dos $26 \%$ de crescimento no setor, enquanto crescimentos mais modestos são esperados para Estados Unidos e Canadá (entre 10\% e 15\%). A União Europeia não deve ultrapassar os 4\% (OECDFAO, 2010). Esse crescimento vertiginoso deve-se principalmente ao incentivo para o desenvolvimento da tecnologia como mecanização, biotecnologia, às condições econômicas e as climáticas.

Apesar da previsão do crescimento da produção agrícola, estima-se que até 2050 a população mundial deverá alcançar entre 9 e 11 bilhões 
de pessoas, o que vai exigir que, no mínimo, seja dobrada a produção de alimentos e, de preferência, sem aumentar drasticamente a área plantada, minimizando assim o impacto sobre nossa biodiversidade (JAMES, 2011). Tecnologias com ganhos rápidos e direcionados, como a engenharia genética serão fundamentais para que esse objetivo seja alcançado, na tentativa de aumentar essa produção seja por ganhos com produtividade ou diminuição de perdas por fatores bióticos ou abióticos sem, no entanto, provocar efeitos irreparáveis ao ambiente.

Nesse sentido, o Brasil vem crescendo substancialmente sua produção de alimentos por meio de processos biotecnológicos e será parte fundamental para suprir considerável parcela de alimentos que o mundo demandará. Em apenas 8 anos, o país já possui a segunda maior área de transgênicos plantados no mundo. E pelo quinto ano consecutivo, a agricultura brasileira foi a que mais impulsionou o crescimento mundial da área plantada com variedades geneticamente modificadas, com ampliação de $12 \%$ na comparação com 2011, atingindo a marca recorde de 36,6 milhões de hectares, um incremento de mais 4 milhões (JAMES, 2012).

A área das principais commodities do agronegócio brasileiro (soja, milho e algodão), provenientes da biotecnologia continuará aumentando, principalmente com relação as variedades com genes que conferem resistência a herbicidas e pragas. Na cultura da soja, a Céleres Consultoria estima que aproximadamente $90 \%$ de todo o plantio para a safra 2012/2013 utilize sementes de origem biotecnológica, o que significa aumento de quase três milhões de hectares se comparado à safra de 2011 . Para o milho safrinha, a expectativa é que a área plantada atinja sete milhões de hectares plantados com híbridos transgênicos, um aumento de $20 \%$ em relação ao ano anterior. Em contrapartida, a safra tradicional (milho verão) poderá chegar a 5,4 milhões de hectares com biotecnologia, um aumento de 7\% em relação a 2011.

Esta Consultoria também prevê que a área semeada com algodão transgênico cresça aproximadamente 94 mil hectares e chegue a quase 550 mil hectares, um aumento de 17\%, devido, principalmente a adoção da biotecnologia. Área com lavouras transgênicas devem totalizar 
36,6 milhões de hectares no ano agrícola 2012/13, com crescimento de 4,0 milhões de hectares $(+12,3 \%)$ em comparação ao ano anterior. (CÉLERES, 2013).

Entretanto, devido à atrasada legalização de plantios transgênicos ocorrida em 2005, o país ainda importa praticamente toda a tecnologia. Em contrapartida, em 2012 o Brasil aprovou sua primeira variedade transgênica genuinamente desenvolvida no Brasil, o feijão resistente ao vírus do mosaico dourado, doença que pode provocar perdas de $40 \%$. Novos produtos vêm sendo desenvolvidos para a liberação ainda esse ano, principalmente para espécies de grande importância no país, buscando assim, o fortalecimento de economias regionais.

A maior vantagem da produção de OGMs nacionais, produzidos por Universidades ou pela Embrapa, concerne no fato de que, o agricultor brasileiro contaria com mais opções para sua escolha. A Embrapa está definindo um sistema que permite o acesso do produtor brasileiro à tecnologia sem elevação de custos, e também que preserve os direitos da instituição quando outras empresas lucrarem com a alternativa, quando associada a um feijão de propriedade de uma empresa privada, por exemplo. Assim, pequenos e grandes produtores poderão se beneficiar com as tecnologias desenvolvidas pelas instituições nacionais, aumentando assim a produção e a competição no mercado internacional.

\section{Conclusões}

Embora o agronegócio seja imprescindível ao desenvolvimento nacional e internacional, inclusive no que concerne à geração de empregos, rendas e tributos, seu aperfeiçoamento torna-se necessário para suprir a crescente demanda de alimentos da população. O aperfeiçoamento do agronegócio passa pelo desenvolvimento de pesquisa tecnológica para aumento de produtividade e pela recuperação das áreas atualmente degradadas. Nesse contexto a pesquisa em biotecnologia surge como uma alternativa racional para garantir maior retorno financeiro para o agronegócio, bem como conservação do ambiente. 
Enquanto o agronegócio apresenta forte expansão ao longo das últimas décadas, a pesquisa em biotecnologia ainda precisa de novos de investimentos, principalmente em países em desenvolvimento para que possa desenvolver suas potencialidades.

Com o investimento para a pesquisa e desenvolvimento de variedades de plantas transgênicas em países em desenvolvimento, pequenos e médios produtores poderão se beneficiar e melhorar sua renda, diminuindo assim, o êxodo rural. Nesse sentido, a transformação genética pode ser também, o motor de uma transformação social sistemática.

\section{Referências}

BAER, W. Economia Brasileira. 2º ed. São Paulo: Ed. Nobel, 2002.

BARROS. G. S. C; ADAMI, A. C. O. Exportações do agronegócio batem novo recorde em 2012, mesmo comqueda de preços. CEPEAESALQ/USP. Piracicaba, 2013. Disponível em $<$ http://w.cepea.esalq. usp.br/comunicacao/Cepea_ExportAgro_2012.doc $>$. Acesso em: 12 mai. 2013.

BORÉM, A.; ALMEIDA, G. D. Plantas geneticamente modificadas: desafios e oportunidades para regiões tropicais. Viçosa: Ed. UFV. 2011. BORÉM, A.; FRITSCHE NETO, R. (Eds.). Biotecnologia Aplicada ao Melhoramento de Plantas. Visconde do Rio Branco, MG: Suprema, 2013.

BRASIL. Comissão Técnica Nacional de Biossegurança. Lei 11.105 de 24 de março de 2005. Dispõe sobre as normas de segurança e mecanismos de fiscalização de atividades que envolvam organismos geneticamente modificados - OGM e dá outras providências. Diário Oficial da União, Brasília. 28 mar. 2005. 
BROOKES, G.; BARFOOT, P. Forthcoming. GM Crops: Global socioeconomic and environmental impacts 1996-2010, PG Economics Ltd, Dorchester, UK. 2012.

CÉLERES. Os benefícios econômicos da biotecnologia agrícola no brasil: 1996/97 - 2011/2012. Disponível em: <http://celeres.com.br/ wordpress/wp-content/uploads/2013/01/PressRelease2012_Economico. pdf. >. Acesso em: 20 mai. 2013.

CÉLERES. Relatório Biotecnologia. Relatório Técnico. Disponível em: <http://celeres.com.br/wordpress/wp-content/uploads/2012/12/ RelBiotecBrasil_1201_vf.pdf.> Acesso em: 15 mai. 2013.

CEPEA. GPD AGRIBUSSINES - Brazil Outlook. Relatório PIBAgroBrasil. Dezembro 2012. Disponível em: < http://www.cepea.esalq.usp. br/comunicacao/Cepea_PIB_BR_abr13.pdf > .Acesso em: 12 mai. 2013.

CIB. Milho transgênico aumenta em 34\% a produtividade de pequeno produtor na África do Sul. Conselhos de Informações sobre Biotecnologia. 31 jan. 2008.

CTNBio. Aprovações Comerciais. Disponível em: <http://www.ctnbio. gov.br/index.php /content/view/12786.html>. 2012. Acesso em: $19 \mathrm{dez}$. 2012.

FDA. FDA Extends Comment Period on AquAdvantage Salmon Documents. Disponível em: <http://www.fda.gov/ AnimalVeterinary/DevelopmentApprovalProcess/GeneticEngineering/ GeneticallyEngineeredAnimals/ucm280853.htm>. 2013. Acesso em: 14 mai. 2013.

\section{FEU-US. The Food Gap: The Impacts of Climate Change on Food} Production: A 2020 Perspective.. Disponível em: <http://www.feu-us. org/images/The_Food_Gap.pdf>. 2011. Acesso em: 25 mai. 2013. 
FMI. World Economic Outlook - Hopes, Realities, Risks. WORLD ECONOMIC AND FINANCIAL SURVEYS. Relatório Técnico. Disponível em: $<$ http://www.imf.org/external/pubs/ft/weo/2013/01/ pdf/ text.pdf.>. 2013. Acesso em: 02 jun. 2013.

GATES, B. Innovation with Impact: Financing 21st Century Development. Disponível em: <http://www.scidev.net/en/science-andinnovation-policy/innovation-policy/news/gates-tells-g20-innovationis-the-key-to-development.html.> 2011. Acesso em: 06 jun. 2013.

GRECO, A. Transgênicos, o Avanço da Biotecnologia. São Paulo: Oirã. 2009.

JAMES, C. Global status of commercialized biotech/GM Crops: 2011. Disponível em: <http://www.isaaa.org.> 2011. Acesso em: 12 abr. 2012.

\section{JAMES, C. Global status of commercialized biotech/GM Crops:}

2012. Disponível em: <http://www.isaaa.org/resources/publications/ briefs/44/>. 2012. Acesso em: 15 abr. 2013.

KATHAGE, J; QAIM, M. Economic impacts and impact dynamics of Bt (Bacillus thuringiensis) cotton in India. Proc Natl Acad Sci. 2012; 109(29).

NAGAYETS, O. SMALL FARMS: CURRENT STATUS AND KEY TRENDS. Information Brief prepared for the Future. Proceedings of a Research Workshop. Wye College. Jun 26-29, 2005.

OECD-FAO Agricultural Outlook 2010-2019. Disponível em: $<$ http:// www.ti.bund.de/fileadmin/dam_uploads/Institute/MA/ma_de/maallgemein/OECD-Seminar/Additional_Information/OECD $\% 20 \mathrm{FAO} \% 20$ outlook.pdf.> 2010. Acesso em: 12 mai. 2013. 